Geografia e Ordenamento do Território, Revista Electrónica

Centro de Estudos de Geografia e Ordenamento do Território

http://cegot.org

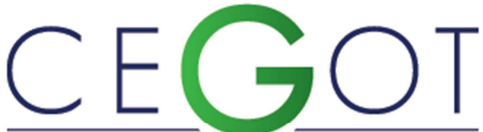

Centro de Estudos de Geografia e Ordenamento do Território
ISSN : 2182-1267

Nogueira, M.

Departamento de Geografia; Instituto de Geociências; Universidade Federal de Minas Gerais

marlynogueira.geo@gmail.com

\title{
Impactos socioeconômicos dos benefícios previdenciários em pequenas cidades do Estado de Minas Gerais, Brasil
}

Referência: Nogueira, M. (2013). Impactos socioeconômicos dos benefícios previdenciários em pequenas cidades do Estado de Minas Gerais, Brasil. Revista de Geografia e Ordenamento do Território (GOT), n.o 4 (dezembro). Centro de Estudos de Geografia e Ordenamento do Território, p. 177-196

\section{Resumo}

O Brasil, um País de dimensões continentais e com uma população de praticamente 200 milhões de habitantes, é igualmente, marcado tanto por sua diversidade, não somente da natureza, como sobretudo pelas desigualdades sociais e regionais. A Previdência Social, enquanto política de proteção e segurança, é uma das grandes conquistas do trabalhador formal brasileiro. Sendo assim, considerando a função da Previdência Social no processo de redistribuição de renda e diminuição das desigualdades sociais, este trabalho, analisa criticamente a importância dessa instituição para a socioeconomia de cinco pequenas cidades do Estado de Minas Gerais.

Palavras-chave: INSS, redistribuição de renda, pequenas cidades, Minas Gerais, Brasil.

\begin{abstract}
Brazil, a country of continental dimensions and with a population of almost 200 million inhabitants, is marked by its diversity, not only nature, but also social and regional imbalances. Social Security, a policy of protection and safety, is one of the great achievements of the Brazilian formal worker. This article analyzes the importance of this institution for the socioeconomics of five small towns of Minas Gerais, considering the
\end{abstract}


role of Social Security in the process of income redistribution and reduction of social inequalities.

Key words: INSS, income redistribution, small towns, Minas Gerais, Brazil.

\section{Introdução}

O estudo das cidades é uma das temáticas mais tradicionais da Geografia. No entanto, nos últimos cinquenta anos houve clara priorização para o estudo das metrópoles e, num segundo momento, as cidades médias passaram a ser foco de pesquisas de forma mais constante. Por outro lado, embora em menor quantidade, ultimamente vem-se observando um considerável crescimento das pesquisas envolvendo as pequenas cidades na Geografia. Este crescimento pode ser explicado, entre outros fatores, pela refuncionalização de pequenas cidades, em decorrência da nova configuração da rede urbana, alavancada pelo processo de globalização (Corrêa, 1999, 2011)

Entre os 5.564 municípios brasileiros, os considerados pequenos são a maioria e neles vive uma boa parte da população do País. O presente trabalho trata da temática das pequenas cidades, objetivando desvelar o impacto socioeconômico da Previdência Social em cinco pequenos municípios brasileiros, de Minas Gerais: Carneirinho, Central de Minas, Delfim Moreira, Passa Tempo e São João das Missões. Cada município objeto de estudo localiza-se numa região diferente do Estado (Figura 1).

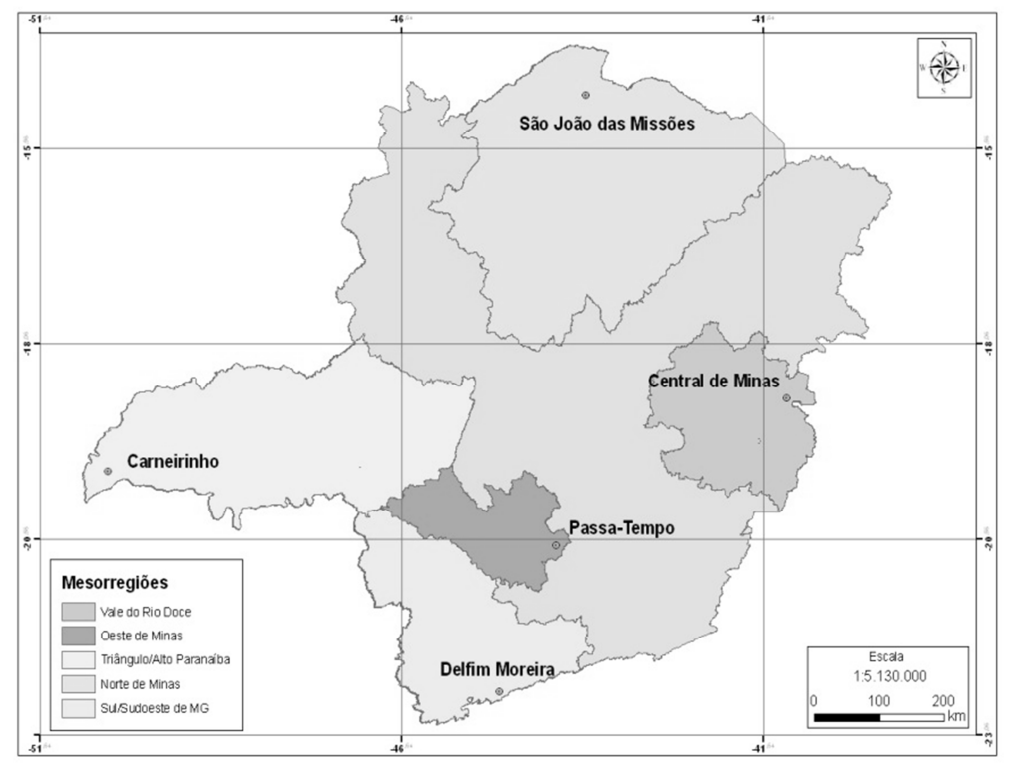

Figura 1 - Minas Gerais: localização geográfica dos municípios selecionados 
Considerando-se a heterogeneidade socioeconômica e geográfica do Estado de Minas Gerais, onde os municípios foram selecionados de acordo com as particularidades de cada uma das regiões constituindo fatores que diferenciam os cinco municípios. Assim, selecionaram-se cinco municípios com dimensão populacional semelhante (de 5000 a 15000 habitantes), mas, também, com localizações abrangendo algumas regiões do Estado consideradas desenvolvidas e outras deprimidas, fato que propicia uma visão mais ampla do fenômeno estudado.

Em relação à Previdência Social, um assunto de interesse público e que está constantemente em voga nos debates de diferentes agentes sociais, o interesse pelas pequenas cidades se dá no intuito do melhor conhecimento do declarado papel de redistribuição de renda que é atribuído a essa instituição. A possibilidade de pesquisar a importância da Previdência Social para os pequenos municípios, torna-se uma experiência enriquecedora, haja vista que esta temática pode envolver questões interessantes nas pesquisas em Geografia Econômica, na Economia, em Políticas Públicas, na Sociologia e no Planejamento Regional.

Ao se considerarem os dados socioeconômicos dos cinco municípios, são apresentados os dados referentes aos benefícios da Previdência Social, analisando seus impactos nas economias locais. São também comparados os dados estatísticos contendo os valores dos benefícios emitidos e arrecadados em cada município. É dado um enfoque aos benefícios em que a contribuição do segurado para com a Previdência Social não é obrigatória - trabalhadores rurais e do Benefício de Prestação Continuada da Lei Orgânica de Assistência Social - BPC-LOAS. A partir disso pode ser analisado o papel da Previdência Social na redistribuição de renda para a população mais pobre, nos pequenos municípios em tela. Por fim, a título de considerações finais, tem-se uma comparação entre os municípios, levando-se em conta as peculiaridades econômicas, políticas, espaciais e sociais de cada um. Desse modo, busca-se apresentar as tendências e entraves que envolvem uma possível dependência dos benefícios previdenciários por parte desses municípios e as possibilidades dos mesmos em busca de maior autonomia econômica. 


\section{Breves considerações sobre as pequenas cidades: aspectos teórico-metodológicos}

O estudo das pequenas cidades vem ganhando certo relevo e entre as principais contribuições para a temática das pequenas cidades, vale a pena destacar as de geógrafos como Santos (1993, 1979 a, b), Corrêa (1999, 2011), Damiani (2006) e Spósito (2006 e 2010), além das de Wanderley (1996, 1997), por exemplo. Ainda assim, os estudos sobre as pequenas cidades no Brasil carecem de mais avanços metodológicos e conceituais, de mais reflexão teórica.

O Instituto Brasileiro de Geografia e Estatística - IBGE, utiliza como critério de definição de cidade, a população. Cidades pequenas são as que possuem menos de 100 mil habitantes. Entretanto, essa classificação baseada exclusivamente num critério demográfico não é bem aceita entre a maioria dos geógrafos, uma vez que existem outros aspectos e processos a serem considerados, no sentido de criar uma conceituação rigorosa e ampla, tendo em vista, a heterogeneidade dos tipos de cidades no Brasil. Além desses fatores, cabe mencionar que a estrutura agrária regional e a centralidade exercida pela pequena cidade em seu entorno são aspectos relevantes que marcam a heterogeneidade das pequenas cidades brasileiras. Desse modo, importa recorrer ao que diz Santos (1979 a, p. 50): “(...) poderíamos então definir a cidade local como a aglomeração capaz de responder às necessidades vitais mínimas, reais ou criadas, de toda uma população, função esta que implica uma vida de relações."

O estabelecimento de um conceito definitivo poderia estar permeado de inconsistências, sujeito a críticas diversas. Ressalte-se que o mais importante não é chegar a um conceito que reúna unanimidade entre os estudiosos do tema, mas sim ampliar as pesquisas sobre esta temática, já que as pequenas cidades são a maioria no Brasil e nelas vive uma parcela significativa da população. É possível apontar características comuns entre elas, considerando-as como pontos na rede de cidades, não se prendendo somente ao modo de vida e à organização do espaço intraurbano de cada uma delas (Corrêa, 2011).

O papel desempenhado pelas pequenas cidades no Brasil vem sofrendo significativas alterações ao longo do tempo, sobretudo no final do século XX e início do atual, quando o processo de globalização se intensifica, gerando mudanças políticas, econômicas, culturais e nas relações sociais das pequenas cidades e nas regiões nas quais estão 
inseridas. Um dos fatores mais expressivos dessa mudança tem a ver, claramente, com a modernização agrícola, afinal, as atividades agrárias sempre marcaram as pequenas cidades brasileiras. Por outro lado, o aumento gradativo nos índices de urbanização parece ter minimizado o caráter rural das pequenas cidades.

A minimização do caráter rural das pequenas cidades intensificou-se em torno dos anos de 1950, quando o Brasil era bem menos urbanizado e industrializado. Essas cidades exerciam importante papel na vida econômica, social e política nas relações do urbano com o rural, como aponta Corrêa (2011, p. 4):

A pequena cidade constituía um nó fundamental na rede de relações econômicas envolvendo o urbano e o rural. Situava-se no começo de uma longa cadeia de comercialização, beneficiamento, se necessário, de produtos do mundo rural. Por outro lado, situava-se no fim de outra cadeia, a de distribuição de produtos industrializados, provenientes de fora, sobretudo das grandes cidades. Alguns produtos industrializados, contudo, eram produzidos localmente, visando o mercado local.

A partir da segunda metade do século XX foram diversas as transformações nas dimensões econômica, política, social, cultural e espacial das pequenas cidades, em decorrência de fatores como a industrialização, urbanização, modernização agrícola e globalização. Ao mencionar as referidas transformações Corrêa (2011) faz uma projeção para as três primeiras décadas do século XXI, admitindo que existem cinco padrões ideais funcionais de pequenas cidades, podendo haver combinações entre elas, prósperos lugares centrais, pequenos centros funcionalmente especializados, pequenas cidades transformadas em subúrbios dormitório, focos de concentração de trabalhadores agrícolas e núcleos dependentes de recursos externos. Vale a pena mencionar que a ocorrência dos diferentes padrões sugeridos pelo autor se poderá dar de forma heterogênea no território nacional, podendo nem ocorrer em determinadas regiões, tendo em vista as diferenças espaciais, como características físicas da região ou o nível de desenvolvimento ou depressão econômica da mesma. De qualquer maneira, uma das características das pequenas cidades é que elas são expressivas em quantidade nos territórios nacionais.

No Brasil, as pequenas cidades, tendo como base a classificação do IBGE, somariam, a partir de dados do censo 2010, mais de 95 \% do total de municípios do país. Sua população soma quase metade da população brasileira. A quantidade de pequenas 
cidades se torna mais expressiva quando o território analisado é o Estado de Minas Gerais, no qual 96,6 \% dos municípios é constituído pelos pequenos, enquanto em relação à população, uma percentagem maior se encontra em pequenos municípios.

Conforme comenta Corrêa (1999), a grande quantidade de pequenas cidades gera uma rede de centros urbanos, de tal forma que, em regiões mais povoadas há um maior número de centros, apresentando uma menor distância entre si. De modo análogo, as regiões menos povoadas, dispõem de um menor número de centros com maior distância entre eles. A grande quantidade de pequenos centros decorre da necessidade de uma economia de mercado, que produz trocas baseadas em uma mínima divisão territorial do trabalho. Existe uma demanda por produtos e serviços, associada a limitações de mobilidade espacial, que apesar de minimizada com o passar do tempo, ainda configura uma realidade em pequenas localidades. Em resposta a essa demanda e limitação de mobilidade há um crescimento no número de pequenos centros de mercado que atendem a população dentro de uma distância mínima acessível. Uma importante característica dos pequenos centros locais é a sua força de inércia, pois eles funcionam também como lugares de sociabilidade, de convivência, resistindo a alterações do espaço e do tempo, transformando-se funcionalmente, o que confere certa segurança na manutenção de sua importância para a sociedade local.

Apesar do difícil exercício em se conceituar as pequenas cidades, Corrêa (2011) ressalta a importância da formulação de um conceito, mesmo que incompleto e com algumas inconsistências, para o estudo dessas localidades, principalmente no que tange ao seu papel na rede de cidades. Segundo o referido autor, a pequena cidade é oriunda de variadas gêneses, como a ação de agentes sociais, padrão de localização, elementos motivadores, entre outros, que estimulam a necessidade e possibilidades de núcleos de povoamento. A pequena cidade é vista como um núcleo de povoamento, no qual a população está dividida, em diferenciadas proporções, em atividades ligadas ao setor urbano e atividades agrárias. Ela pode ser caracterizada como uma transição, com uma maior integração do rural/urbano, sem que haja um rígido limite entre estes. Mas, para ser uma pequena cidade não basta ser um núcleo urbano, deve haver um padrão dominante no que diz respeito à presença da função político-administrativa.

No conjunto de características que conceituam a pequena cidade, o referido autor valoriza a importância da pequena cidade, ao ressaltar a necessidade de se investigar 
desde o grau de centralidade até ao tamanho demográfico; caracterizando-se assim a cidade pequena por ser um centro local, isto é, um centro que exerce centralidade em relação ao seu próprio território municipal. Adverte ainda o mesmo autor, que as pequenas cidades brasileiras e seus hinterlands são muito distintas entre si, devido, entre outros fatores, à diversidade da matriz cultural e à antiguidade do povoamento da área na qual estão inscritas, adicionadas à estrutura agrária e à densidade demográfica da região, bem como às relações com o mercado, o nível de renda da mesma e a acessibilidade.

\section{O impacto socioeconômico dos benefícios previdenciários - análise dos municípios de Carneirinho, Central de Minas, Delfim Moreira, Passa Tempo e São João das Missões}

\subsection{A Previdência Social no Brasil e o Fundo de Participação dos Municípios - FPM}

A Previdência Social brasileira, organizada sob forma de regime geral, é um tipo de política pública que visa, mediante contribuição e filiação obrigatória, oferecer proteção social aos indivíduos, por meio da concessão de benefícios previdenciários no período de inatividade dos segurados. Esta funciona como um seguro, exercendo o papel de reposição de renda aos trabalhadores em situação de risco social: acidente do trabalho, incapacidade temporária ou permanente para o trabalho, maternidade, enfermidade, morte, idade avançada, entre outros. O Benefício de Prestação Continuada - BPC/LOAS é o benefício de amparo assistencial destinado a pessoas que não têm condições financeiras de contribuir para a Previdência Social (idosos a partir de 65 anos de idade e os portadores de deficiência incapacitados para o trabalho e para uma vida independente). O trabalhador rural tem direito aos benefícios previdenciários, independentemente de sua contribuição mensal, precisando para isso apresentar documentação exigida pela legislação que comprove o exercício da atividade rural. Assim, por não haver exigência de contribuição mensal obrigatória ao INSS, o BPC/LOAS e os benefícios rurais assumem o caráter de uma política pública de assistência social, exercendo um importante papel de redistribuição de renda para a parcela significativa da população mais pobre do País. 
O impacto socioeconômico da Previdência Social é mais significativo nos pequenos municípios, onde geralmente o valor da arrecadação, por meio das contribuições ao INSS, é superado pelo valor da emissão de benefícios pela Previdência. Os benefícios rurais que têm caráter não contributivo ou semicontributivo são emitidos majoritariamente nos pequenos municípios. É importante a reflexão em torno do papel de transferência e redistribuição de renda exercido pela Previdência Social, tanto no urbano e no rural, como entre os municípios.

O Fundo de Participação dos Municípios - FPM, por outro lado, é uma das transferências constitucionais de recursos para os municípios. A transferência do FPM é constituída por 22,5 \% da arrecadação líquida do Imposto de Renda e do Imposto sobre Produtos Industrializados. O cálculo das quotas individuais de cada município obedece a critérios distintos. O principal é populacional, ou seja, a partir de determinado coeficiente, para cada faixa de população, conforme divulgação anual da estatística populacional do IBGE, é divulgado o coeficiente de cada município. Os recursos do FPM são muito expressivos para os municípios, especialmente para os pequenos, que normalmente têm, neste fundo, sua principal fonte de receitas. No caso dos cinco municípios em estudo, verificou-se que os valores do FPM são muito mais significativos que a soma de todas as outras transferências feitas, representando entre $62,1 \%$ e $80,5 \%$ do total das transferências realizadas no ano de 2009.

\subsection{Os benefícios da Previdência Social e a economia dos cinco municípios selecionados}

Conforme acima relatado, via de regra, a tendência da emissão de benefícios da Previdência Social superar a arrecadação nos pequenos municípios brasileiros é confirmada em quatro dos cinco municípios aqui estudados, à exceção de São João das Missões, onde não houve arrecadação. Adicionalmente, em Delfim Moreira e Passa Tempo a relação emissão/arrecadação foi a mais significativa na discrepância entre um e outro. No primeiro, a emissão de benefícios foi 11,8 vezes maior que a arrecadação, enquanto que no segundo foi 9,4 vezes mais. Dessa forma, assume-se que a baixa taxa de emprego formal seja a principal causa para a baixa arrecadação desses cinco municípios. 
A precária situação de São João das Missões deve estar ligada à sua muito baixa taxa de emprego formal, apenas 6,30\% (FJP - IMRS, 2010), típica de uma economia bastante deprimida e dependente de investimentos da administração pública. É preciso levar em conta, também, que a capacidade e/ou possibilidade de contribuição está relacionada a fatores como tipo de ocupação, situação do domicílio (rural/ urbano), educação, etc. Acrescente-se ainda, o fator da emigração, uma das características do município. (Figura 2)

A emissão de benefícios, em número muito superior ao que se arrecada nos diversos municípios é fator que, os coloca como beneficiados no processo de redistribuição de renda da Previdência Social, pois os recursos para preencher a lacuna entre emissão e arrecadação, virão de municípios onde há superavit. Normalmente, são os municípios maiores que, apresentam superavit no comparativo em questão, como destacam Barbosa e Costanzi (2009, p. 3):

Na faixa de municípios com mais de 100 mil habitantes, há um volume de arrecadação superior ao de benefícios, em $\mathrm{R} \$$ 3,4 bilhões, o que corresponde a $0,2 \%$ do PIB dessas cidades. Nas demais, o volume de despesas com pagamento de benefícios é superior à arrecadação.

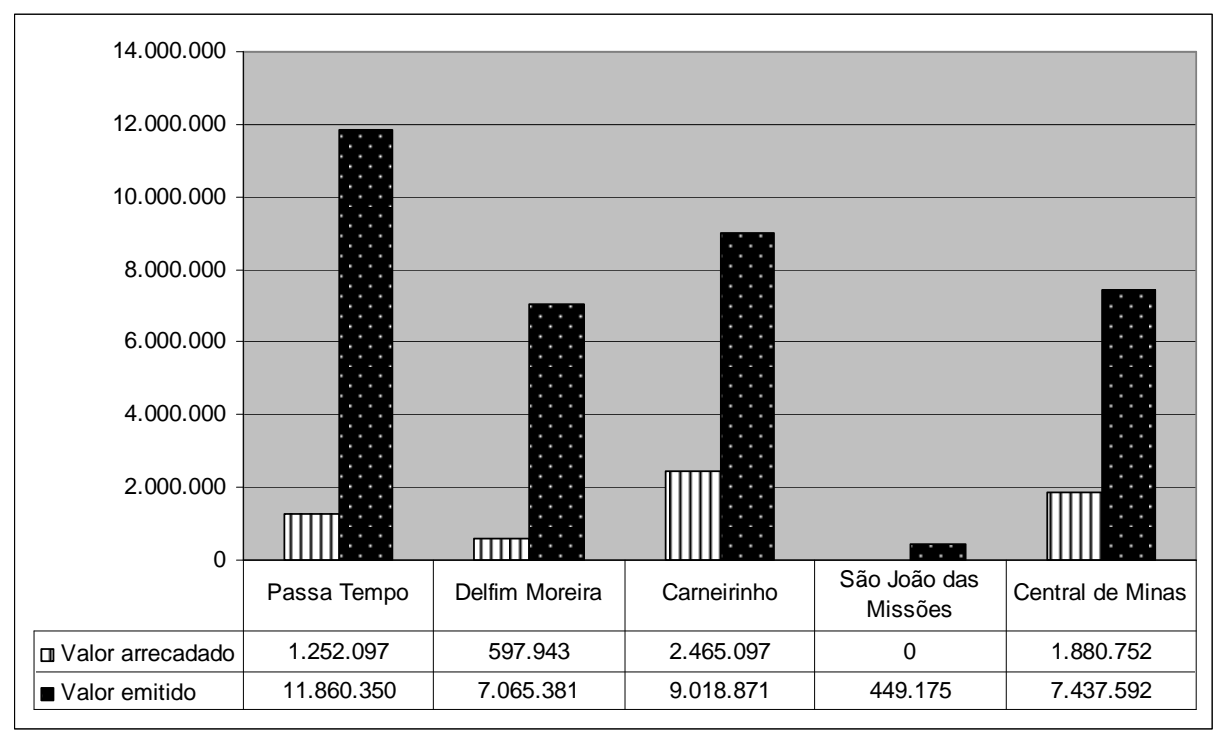

Fonte: Ministério da Previdência Social.

Figura 2: Benefícios previdenciários: valores (R\$) arrecadados/ emitidos Municípios selecionados , 2009 
Portanto, considerando que $95 \%$ dos municípios brasileiros possuem população inferior a 100 mil habitantes e entre estes a arrecadação é menor que a emissão de benefícios, pode-se dizer que o papel de redistribuição de renda da Previdência que ocorre entre os municípios se dá dos maiores e mais ricos para os menores e mais pobres.

Como o FPM é a mais importante transferência feita pela União para os cinco municípios em estudo, a sua confrontação com outra receita de igual importância torna-se um interessante parâmetro comparativo. Em Minas Gerais, o pagamento em benefícios pela Previdência superou o FPM em 533 dos 853 municípios, o que representa mais de $62 \%$ do total. Já no caso específico dos municípios em tela, o FPM é superado por quatro entre os cinco. (Figura 3)

Passa Tempo destaca-se, pois o valor dos benefícios emitidos é 3,3 vezes maior que o do FPM. Em Carneirinho, Central de Minas e Delfim Moreira os valores dos benefícios são um pouco acima do dobro dos do FPM e, finalmente, em São João das Missões, município que recebe o maior valor do FPM (população mais numerosa), este supera os benefícios previdenciários em mais de 10 vezes ${ }^{1}$.

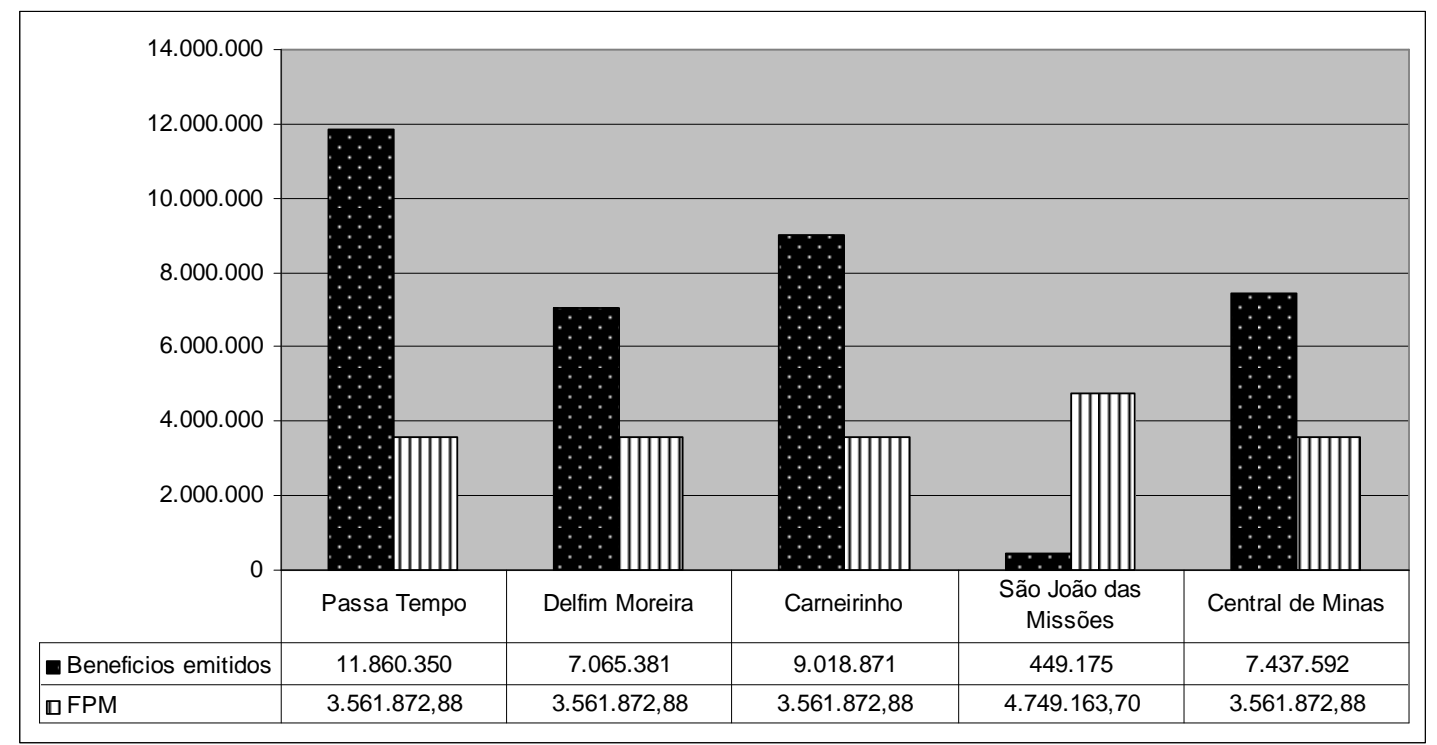

Fonte: Ministério da Previdência Social e Tesouro Nacional.

Figura 3: Benefícios emitidos pelo INSS X FPM - Municípios selecionados , 2009 (R\$)

\footnotetext{
${ }^{1}$ Segundo Teixeira (2008), um dos fatores que limita a concessão de benefícios rurais para a numerosa população indígena (de São João das Missões) é a dificuldade dos trabalhadores rurais possuem em reunir a documentação exigida pelo INSS, comprovando a atividade rural, além da precariedade da documentação civila dessa população.
} 
É importante ressaltar que os recursos do FPM ao serem repassados para as prefeituras locais serão utilizados para diversos fins, podendo ou não ser revertidos em políticas sociais. Mas, uma vez que os benefícios previdenciários representam a renda recebida diretamente pela população, como o fluxo de capital nessas cidades é pouco intenso, a renda proveniente dos benefícios torna-se importante para aumentar a dinâmica das economias das cidades em tela.

Embora se saiba que o PIB é um indicador que representa apenas uma média e não necessariamente a renda da população, aqui admite-se a sua validade para uma outra análise, com fins de comparação com os benefícios previdenciários. A análise consiste em calcular a percentagem a que esses benefícios líquidos equivalem em relação ao PIB total de cada município. Tal exercício objetiva tão somente um parâmetro comparativo, uma vez que os benefícios previdenciários não são contabilizados na estimativa do PIB municipal, embora exerçam influência direta na renda dos beneficiários em cada município.

Em Delfim Moreira e Central de Minas os benefícios líquidos mostram-se mais significativos em relação ao PIB total, ou seja, a participação destes foi de, respectivamente $15,8 \%$ e 13,5 \%. Por outro lado, em Passa Tempo, embora o PIB some mais que o dobro daqueles dos dois municípios citados, em termos absolutos, o impacto de tais benefícios na economia desse último é muito mais relevante.

Excetuando-se as peculiaridades de São João das Missões, observa-se nos restantes municípios a tendência do PIB municipal ser inversamente proporcional à relação entre benefícios líquidos / PIB. Assim, em Carneirinho e Passa Tempo, os maiores valores do PIB, a relação benefícios líquidos / PIB é menor. Por outro lado, Central de Minas e Delfim Moreira, onde os PIB são menores, a relação benefícios líquidos / PIB é maior (Tabela 1). 
Tabela 1: Relação entre benefícios líquidos (2007) e PIB total (2007) - municípios selecionados

\begin{tabular}{|c|c|c|c|c|c|}
\hline Município & $\begin{array}{c}\text { Emissão (1) } \\
(\mathbf{R})\end{array}$ & $\begin{array}{l}\text { Arrecadação } \\
\text { (2) (R\$) }\end{array}$ & $\begin{array}{l}\text { Benef. Líquidos } \\
\text { (3)=(1)-(2) (R\$) }\end{array}$ & $\begin{array}{c}\text { PIB total [4] } \\
\text { (R\$) }\end{array}$ & $\begin{array}{c}(3) /(4) \\
(\%)\end{array}$ \\
\hline Carneirinho & 6.349 .391 & 3.108 .682 & 3.240 .709 & 115.211 .000 & 2,8 \\
\hline Central de Minas & 6.004 .436 & 1.628 .706 & 4.375 .730 & 32.407 .000 & 13,5 \\
\hline Delfim Moreira & 5.677 .467 & 270.721 & 5.406 .746 & 34.186 .000 & 15,8 \\
\hline Passa Tempo & 9.433 .266 & 998.477 & 8.434 .789 & 77.076 .000 & 10,9 \\
\hline São João das Missões & 242.472 & 0,00 & 242.472 & 26.182 .000 & 0,9 \\
\hline
\end{tabular}

Fonte: Ministério da Previdência Social e IBGE.

Em relação aos benefícios rurais (Previdência e o BPC/LOAS), com forte caráter assistencial para os pequenos municípios, o papel de redistribuição de renda exercido pela Previdência Social é muito expressivo, seja no conjunto do território municipal, seja entre o urbano e o rural (Figura 4).

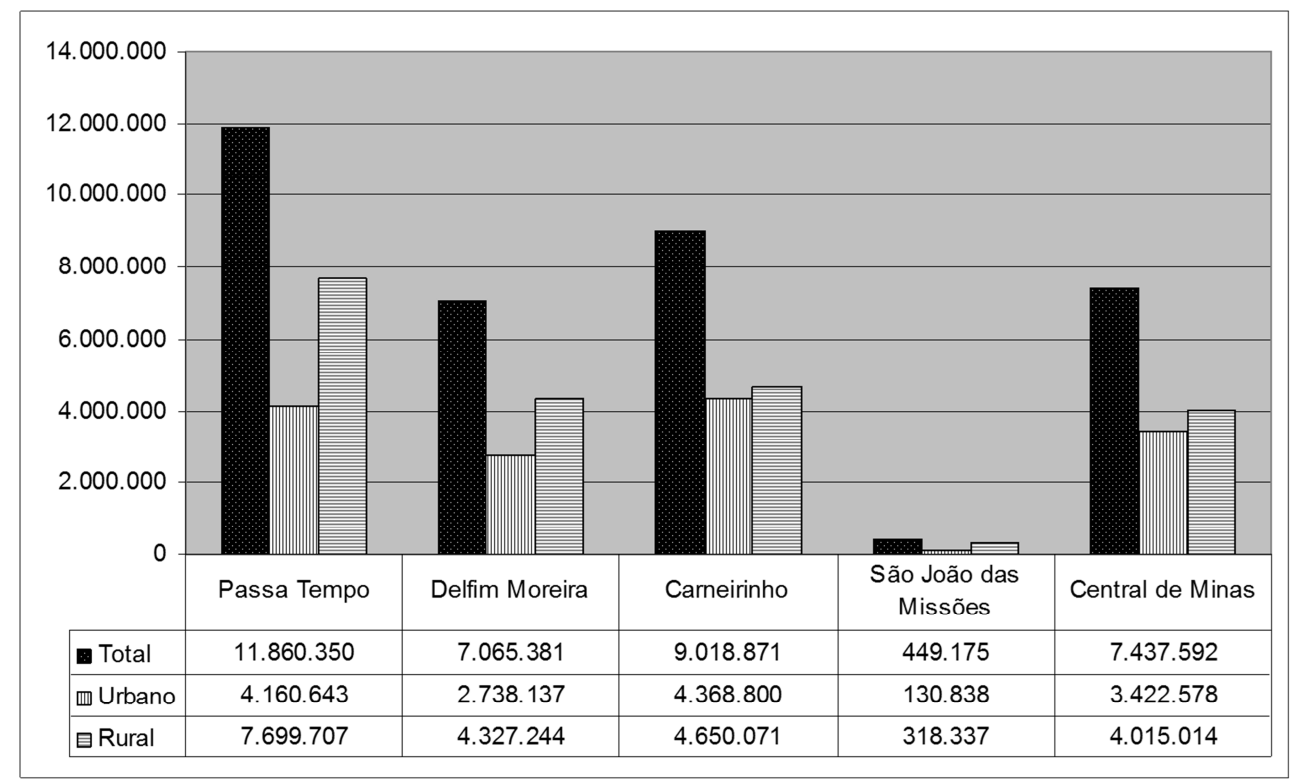

Fonte: Ministério da Previdência Social e Tesouro Nacional.

Figura 4: Valores (R\$) da emissão de benefícios / situação de domicílio, municípios selecionados, 2009

Os valores da emissão de benefícios rurais superaram os valores dos benefícios urbanos em todos os municípios, ainda que apenas São João das Missões $(80,2$ \%) apresente a 
maioria de população rural. Vale lembrar, sem todavia entrar no mérito, o que ressaltam Brito e Horta (2003), acerca da definição de urbano e de rural, pois, no caso de pequenos municípios brasileiros, a divulgação de informações oficiais que caracterizam a população como urbana ou rural pode nem sempre condizer com a realidade, sendo alvo de questionamentos. Passa Tempo retrata bem essa situação, pois enquanto $65 \%$ do valor dos benefícios emitidos no município são rurais, a população considerada urbana é de $75,4 \%$ (IBGE, 2010). Contudo, a despeito dessa discussão, é fato que a maior parte dos benefícios previdenciários emitidos é rural. Considerando que este tipo de benefício independe de contribuição obrigatória, evidencia-se, portanto, o papel de redistribuição de renda da Previdência para os cinco municípios. A possibilidade de acesso à renda por meio de benefícios rurais pode elevar o padrão de consumo, melhorar as condições de habitação e infraestrutura, podendo ainda ser um fator de estímulo para a permanência do trabalhador rural no campo. Para França (2004, p. XV):

O acesso a benefícios da Previdência Rural eleva substantivamente a qualidade de vida do domicílio do beneficiário, proporcionando a melhoria nas características físicas dos domicílios (material das paredes, banheiros e número de cômodos); eleva significativamente o conjunto de residências com acesso às infra-estruturas de água, energia elétrica, instalação sanitária e rede de telefonia; aumenta de maneira expressiva o acesso à casa própria; melhora o acesso aos bens duráveis (fogão a gás, geladeira, rádio, televisão, freezer e antena parabólica); permite-lhe consolidar e investir na agricultura familiar, oferece uma estabilidade de renda básica para seu domicílio em patamares impensáveis para a pequena unidade familiar, antes da Previdência Rural.

Juntamente com os benefícios previdenciários rurais, os BPC/LOAS também não dependem de contribuição obrigatória da parte do beneficiário e, por isso, possuem considerável importância na composição dos benefícios dos municípios. A tabela 2 mostra a representatividade destes benefícios no total concedido no mês de maio/2010, nos cinco municípios considerados neste estudo. 
Tabela 2: Concessão de benefícios - municípios selecionados - maio / 2010

\begin{tabular}{|c|c|c|c|c|}
\hline Município & Total & Total dos rurais & $\begin{array}{l}\text { Total de } \\
\text { BPC/LOAS }\end{array}$ & $\begin{array}{c}\text { Participação dos } \\
\text { Benefícios Rurais e } \\
\text { BPC/LOAS no total } \\
\text { (\%) }\end{array}$ \\
\hline Carneirinho & 1385 & 753 & 263 & 73,4 \\
\hline Central de Minas & 1108 & 644 & 204 & 76,5 \\
\hline Delfim Moreira & 911 & 579 & 87 & 73,1 \\
\hline Passa Tempo & 1767 & 1206 & 88 & 73,2 \\
\hline $\begin{array}{l}\text { São João das } \\
\text { Missões }\end{array}$ & 158 & 114 & 31 & 91,8 \\
\hline
\end{tabular}

Fonte: INSS - Instituto Nacional do Seguro Social / SUIBE - Sistema Único de Informações de Benefícios.

Novamente é em São João das Missões, onde $80,2 \%$ de população é rural, que os dois benefícios tiveram maior participação, com 91,8 \% do total. Em Central de Minas, município com maior índice de urbanização entre os cinco, cerca de $85 \%$, a soma dos dois chegou a 76,5 \% do total. A menor participação registra-se em Delfim Moreira e Passa Tempo, sendo que esse último, também, apresentou o maior número de benefícios emitidos.

Conforme já referido, a Previdência Social possui importante papel de redistribuidora de renda para a população mais pobre, idosa e demais cidadãos em situação de risco social, refletindo uma considerável participação na vida econômica e social dos pequenos municípios. Apesar da diminuição da pobreza em decorrência da expansão da Previdência Social atingir todas as faixas etárias, os idosos normalmente são os mais beneficiados. Entretanto, as mudanças na estrutura demográfica, com o aumento da expectativa de vida, alteram o perfil das demandas por políticas sociais, o que acarreta uma crescente pressão sobre o sistema previdenciário. Sendo assim, um dos indicadores demográficos que influencia diretamente a pressão sobre o sistema previdenciário brasileiro é o índice de envelhecimento (Tabela 3). 
Tabela 3 : Índice de envelhecimento ${ }^{1}$ - municípios selecionados 2000 a 2006 e 2007

\begin{tabular}{|l|c|c|c|c|c|c|c|c|c|}
\hline \multirow{2}{*}{\multicolumn{1}{|c|}{ Município }} & \multicolumn{7}{|c|}{ Ano } & Variação \\
\cline { 2 - 10 } & $\mathbf{2 0 0 0}$ & $\mathbf{2 0 0 1}$ & $\mathbf{2 0 0 2}$ & $\mathbf{2 0 0 3}$ & $\mathbf{2 0 0 4}$ & $\mathbf{2 0 0 5}$ & $\mathbf{2 0 0 6}$ & $\mathbf{2 0 0 7}$ & $\begin{array}{c}\text { 2000-2007 } \\
\text { (\%) }\end{array}$ \\
\hline Carneirinho & 28,20 & 30,02 & 31,84 & 33,78 & 35,78 & 37,83 & 39,84 & 42,44 & 50,5 \\
\hline Central de Minas & 36,56 & 39,43 & 41,96 & 45,01 & 47,80 & 50,57 & 52,69 & 56,02 & 53,2 \\
\hline Delfim Moreira & 26,78 & 27,98 & 29,16 & 30,30 & 31,26 & 32,24 & 33,17 & 34,62 & 29,3 \\
\hline Passa Tempo & 38,10 & 39,86 & 41,75 & 43,55 & 45,52 & 47,38 & 49,39 & 50,77 & 33,3 \\
\hline & & & & & & & & & \\
São João daMissões & 10,51 & 11,11 & 11,73 & 12,47 & 13,21 & 13,95 & 14,68 & 15,0 & 42,7 \\
\hline
\end{tabular}

Fonte: Fundação João Pinheiro - Índice Mineiro de Responsabilidade Social (versão 2010).

1.Índice de envelhecimento = $($ População acima de 65 anos $/$ População entre 0 e 14 anos $)$ *100.

Nos cinco municípios houve um crescimento gradativo do índice de envelhecimento no período de 2000 a 2007. A maior taxa de crescimento ocorreu em Central de Minas, ou seja, 56,2 \%, que também acusa a maior variação no período. São João das Missões e Delfim Moreira apresentaram os menores índices, em 2007, mas somente no primeiro a maioria da população vive na zona rural (IBGE, 2010), fato que pode sugerir uma menor longevidade dessas populações. De uma maneira geral, a tendência de envelhecimento da população e outras mudanças que vêm ocorrendo na estrutura demográfica brasileira são (e devem ser) muito importantes para subsidiar a gestão e avaliação de políticas públicas na área de Previdência Social nacional.

\section{Discussões e Considerações Finais}

O esforço empreendido neste estudo, ao investigar algumas dimensões socioeconômicas de cinco pequenos municípios mineiros, demonstrou que, embora todos eles sejam considerados pequenos e com dimensão populacional semelhante, existem diversos fatores que os distinguem, confirmando que apenas o critério populacional não é suficiente para conceituar ou padronizar os municípios e suas cidades, de maneira geral. Pode-se apontar alguns fatores que diferenciaram estes pequenos municípios, dentre os quais destacam-se: a posição e localização geográficas, 
as particularidades sociais e os tipos de atividades econômicas. Adicionalmente, é um fato que, se configura nas cinco cidades o que Santos (1979 b) chamou de "Circuito Inferior da Economia", uma vez que nelas predominam as atividades de pequena envergadura, com baixo ou nenhum incremento tecnológico, sendo desenvolvidas pela população de baixa renda, com área de atuação sempre local.

Muitas vezes as características municipais coincidem com as apresentadas pela região na qual estão inseridos. São João das Missões, que apresenta os mais baixos indicadores socioeconômicos entre os cinco municípios, isso é verdadeiro, pois o Norte de Minas também apresenta os mais baixos indicadores entre as cinco regiões mineiras, consideradas neste trabalho. Assim, também Carneirinho, o único município entre os cinco no qual a agropecuária foi a responsável pela maior parcela do PIB, fica demonstrada a vocação agropecuária do município como a do Triangulo Mineiro, sua região.

Por outro lado, cabe o destaque para Delfim Moreira, que apresenta, características bastante distintas do Sul de Minas. Em relação ao PIB per capita (IBGE, 2007), enquanto o Sul de Minas apresentou o valor de $\mathrm{R} \$ 12.000$, Delfim Moreira obteve apenas $\mathrm{R} \$$ 4.300, bem abaixo da média regional e quarta colocação entre os cinco municípios, enquanto o Sul só perde para o Triângulo.

Passa Tempo assemelha-se mais ao eixo Divinópolis - Itaúna da região do Centro-Oeste, apresentando um PIB industrial razoável. Já Central de Minas assemelha-se aos municípios do entorno de Governador Valadares, com indicadores socioeconômicos abaixo da média estadual.

Considerando a dimensão da economia dos municípios, na qual o setor terciário, pequeno comércio varejista e serviços da administração pública, representa parcela muito significativa do PIB em todos e tendo em vista os dados referentes aos benefícios previdenciários aqui investigados, é possível constatar que a renda gerada pelo pagamento de tais benefícios exerce um importante papel em suas respectivas economias, pois a renda originada destes é responsável por grande parte do consumo que dinamiza as economias locais, por meio das atividades de consumo de bens e serviços. 
Embora se perceba o importante papel da Previdência Social em relação à socioeconomia dos cinco municípios, afirmar que isso configura uma relação de dependência, merece uma análise mais cuidadosa. Carneirinho é, dentre os cinco, aquele que apresenta os melhores indicadores no PIB total, no PIB per capita, na taxa de emprego e no rendimento médio no setor formal. Poder-se-ia dizer que esse município possui certa autonomia econômica em comparação aos demais. Porém, ainda seriam necessárias maiores ofertas de emprego e de bens e serviços essenciais para a população, para the atribuir a referida autonomia, pois os benefícios previdenciários permanecem bastante significativos na sua redistribuição de renda.

São João das Missões apresenta características econômicas bem peculiares. A predominância da pecuária e agricultura de subsistência está ligada ao modo de vida e à cultura de grande parte da população que é de origem indígena. $\mathrm{O}$ acesso aos benefícios rurais da Previdência Social é uma forma de adquirir renda, mas não interfere com a necessidade do abandono do território e seu modo de vida. Assim, pode-se dizer que os benefícios previdenciários, juntamente com outros programas e políticas públicas, são indispensáveis para a geração de renda no município.

Em Central de Minas e Delfim Moreira, os indicadores socioeconômicos, PIB total, PIB per capita, taxa de emprego e rendimento médio no setor formal, podem ser considerados baixos em relação à média estadual. Além disso, não foi possível verificar nenhuma atividade econômica de grande destaque nesses municípios que possibilitasse vislumbrar melhoras significativas nesses indicadores. Por outro lado, Passa Tempo destaca-se entre as cinco cidades quanto ao IDH (2000), ocupando a 170a posição entre os municípios mineiros e tendo um PIB industrial, com um valor superior à soma dos valores dos outros quatro municípios. Entretanto, o município não apresenta uma base econômica sólida, com possibilidades de expansão de empregos e renda que lhe propiciem autonomia e dinamismo. Assim, ao se considerarem os benefícios previdenciários para os cinco municípios, pode-se afirmar que eles são fundamentais para fortalecer as economias locais, uma vez que a renda gerada é essencial para movimentação, sobretudo dos setores terciários locais.

Tal como ocorre na escala nacional, pode-se dizer que os municípios são os maiores beneficiados no papel de redistribuição de renda exercido pela Previdência Social, uma 
vez que a arrecadação advinda das contribuições ao INSS é bastante deficitária em relação ao que se emite em benefícios nesses municípios. Além disso, o elevado percentual de benefícios que não necessita de contribuição mensal obrigatória, potencializa essa condição de beneficiados. Ressalte-se que as políticas de Previdência Social têm no Estado seu agente formulador e executor, sendo compostas de políticas econômicas e sociais.

Adicionalmente, é preciso mencionar a importância do Programa Bolsa Família, um outro programa de transferência direta de renda que beneficia famílias em situação de pobreza e de extrema pobreza em todo o País. O Bolsa Família, que em 2013 completa dez anos de existência, integra o Plano Brasil Sem Miséria, que tem como foco de atuação uma população de 16 milhões de pessoas com renda familiar per capita inferior da $\mathrm{R} \$ 70,00$ mensais, por meio da garantia de renda, inclusão produtiva e no acesso aos serviços públicos. O Programa possui três eixos principais: o alívio imediato da pobreza por meio da transferência de renda; as condições que reforçam o acesso aos direitos sociais básicos nas áreas da educação, saúde e assitência social e as ações e programas complementares que promovem o desenvolvimento das famílias, de maneira que a situação de vulnerabilidade seja superada; crianças e jovens passam a vislumbrar melhores perspectivas que a de seus pais, rompendo o ciclo vicioso de reprodução da pobreza entre as gerações que tanto caracteriza grande parte da população brasileira, independente do tamanho do município.

Assim, como se pode perceber, as políticas públicas de atenuação e eliminação da pobreza de indivíduos e famílias na escala da União, como o programa acima referido, têm ocupado expressivamente a agenda política do governo federal e, muito embora, não tenha sido alvo de investigação no presente estudo, é evidente que, diante de sua expressiva centralidade,assim como as aqui investigadas (benefícios previdenciários e FPM), esta lacuna carece ser preenchida, na procura da investigação, por exemplo de seu real papel na eliminação ou atenuação da probreza no pequenos municípios brasileiros, tal qual aqui se procedeu em relação aos cinco municípios mineiros selecionados, no que se relaciona aos impactos do benfícios previdenciários e do Fundo de Participação dos Municípios. 
O presente trabalho buscou mostrar que a Previdência Social exerce papel expressivo na redistribuição de renda no País, sendo fundamental para a economia de pequenos municípios; muito embora permaneça a incapacidade desses municípios se tornarem autônomos, diante de um quadro de extrema carência social e econômica. Desse modo, é preciso avaliar as profundas transformações, demográficas, inclusive, sofridas pela população brasileira, diante do aumento constante da exigência de recursos para financiar os direitos previdenciários do cidadão. Faz-se necessária a adoção de políticas que minimizem a informalidade no mercado de trabalho, buscando investir na qualificação da população, com igualdade de acesso a todos. Entretanto, a busca por formas de financiamento da Previdência Social não deve ser baseada nas contribuições monetárias individuais, considerando as desigualdades sociais existentes no País, pois nem toda a população será capaz de manter contribuições regulares. Reitera-se a importância da Previdência Social na redistribuição de renda no País. É preciso que as políticas públicas de previdência social estejam sincronizadas com as demais, sobretudo educacionais, visando mudar a realidade social da maioria dos indivíduos, principalmente os marginalizados, proporcionando-lhes a verdadeira autonomia, tornando-os verdadeiros cidadãos.

\section{5.referências}

Barbosa, Edvaldo Duarte; Costanzi, Rogério Nagamine (2009). Previdência Social e Redistribuição de Renda Intermunicipal. $\quad$ Brasília, $2009 . \quad$ Disponível <http://www.previdenciasocial.gov.br/arquivos/office/3_090608-155706-828.pdf>.Acesso em: 19 jul. 2012.

Brito, Fausto Reynaldo Alves de; Horta, Cláudia Júlia Guimarães (2003). "Concentração Populacional e Fragmentação Político-Territorial no Brasil: o caso de Minas Gerais". In: Encontro Transdisciplinar - Espaço e População e III Encontro Nacional sobre Migrações. Anais. Campinas: ABEP, 2003. Disponível em: <http://www.abep.nepo.unicamp.br/docs/eventos/transdisciplinar/trab_brito.pdf>. Acesso em: 14 jul. 2012.

Corrêa, Roberto Lobato (1999). "Globalização e Reestruturação da rede urbana: uma nota sobre pequenas cidades". Território (6) jan./jun.:43-53.

Corrêa, Roberto Lobato (2011). "As pequenas cidades na confluência do urbano e do rural”. GEOUSP (30):5-12. Disponível em: http://citrus.uspnet.usp.br/geousp/ojs-2.2.4/index.php/geousp/issue/view/33. Acesso em: 10 jul. 2012.

Damianil, Amélia Luísa (2006). "Cidades médias e pequenas no processo de globalização. Apontamentos bibliográficos". En publicacion: América Latina: cidade, campo e turismo. CLACSO, Consejo Latinoamericano de Ciencias Sociales, San Pablo. Disponível em: <http://bibliotecavirtual.clacso.org.ar/ar/libros/edicion/lemos/08damiani.pdf>. Acesso em: 11 jul. 2012.

França, Álvaro Sólon de (2004). Previdência Social e a Economia dos Municípios. Brasília, ANFIP. 
FUNDAÇÃO JOÃO PINHEIRO (2010). IMRS - Índice Mineiro de Responsabilidade Social (versão 2010). Disponível em: http://www.fjp.gov.br/index.php/servicos/82-servicos-cepp/956-indice-mineiro-deresponsabilidade-social-imrs. Acesso em: 12 jul. 2012.

INSTITUTO BRASILEIRO DE GEOGRAFIA E ESTATíSTICA (2010). Censo Demográfico de 2010. Rio de Janeiro. Disponível em> www.ibge.br. Acesso em 9 jul. 2012.

INSTITUTO BRASILEIRO DE GEOGRAFIA E ESTATÍSTICA - COORDENAÇÃO DE CONTAS NACIONAIS / FUNDAÇÃO JOÃO PINHEIRO - CENTRO DE ESTATÍSTICAS E INFORMAÇÕES (2007). PIB - Produto Interno Bruto de Minas Gerais - Anexo Estatístico PIB MG 1995-2007. Disponível em: <http://www.fjp.gov.br/index.php/servicos/81-servicos-cei/58-produto-interno-bruto-de-minas-gerais>. Acesso em: 9 mai. 2012.

INSTITUTO NACIONAL DO SEGURO SOCIAL. SUIBE - Sistema Único de Informações de Benefícios. Informações extraídas em: 19 mai. 2012.

MINISTÉRIO DA PREVIDÊNCIA SOCIAL. Estatísticas. Disponível em: <http://previdenciasocial.gov.br/conteudoDinamico.php?id=423>. Acesso em: 19 mai. 2012.

MINISTÉRIO DA PREVIDÊNCIA SOCIAL - Informes de Previdência Social. Evolução Recente da Proteção Social e seus Impactos sobre o Nível de Pobreza. Disponível em: < http://previdenciasocial.gov.br/arquivos/office/3_100413-155658-979.pdf>. Acesso em: 18 mai. 2012.

Santos, Milton (1979 a). Espaço e Sociedade. Petrópolis, Vozes, 145p.

Santos, Milton (1979 b). O espaço dividido. Os dois circuitos da economia urbana dos países subdesenvolvidos. Rio de Janeiro, Francisco Alves, 187p.

Santos, Milton (1993). A urbanização brasileira. São Paulo, HUCITEC. 157p.

Spósito, M.E.B.; WHITACKER, A. M. (org.) (2006). Cidade e campo: relações e contradições entre urbano e rural. São Paulo, Expressão Popular, 247 p.

Spósito, Maria Encarnação Beltrão (2010). “Novas redes urbanas: cidades médias e pequenas no processo de globalização". Geografia, 35: 51-62.

Teixeira, Ísis Aline Vale (2008). Conhecendo a vida das mulheres Xakriabá: gênero e participação. Tese de Mestrado, Universidade Federal de Minas Gerais, $209 \mathrm{p}$.

TESOURO NACIONAL. Estatísticas/ Fundo de Participação dos Municípios. Disponível em: <http://www.tesouro.fazenda.gov.br/estados_municipios/download/FPM.xls>. Acesso: em: 19 jun. 2012.

Wanderley, Maria de Nazareth Baudel (1996) "Raízes históricas do campesinato brasileiro", XX Encontro Nacional da ANPOCS, Caxambu.

Wanderley, Maria de Nazareth Baudel (1997) "O "lugar" dos rurais; o meio rural no Brasil moderno". SOBER, Anais. XXX Congresso de Economia e Sociologia Rural, Natal. 